\title{
O entendimento do processo saúde-doença e o valor atribuído aos dentes em uma análise comparativa entre formandos de Odontologia e Engenharia Civil da UEPG/PR
}

\author{
The understanding of health-disease process and the value assigned to the teeth in a comparative analysis \\ between the Dentistry and Civil Engineer trainees from UEPG/PR
}

Amanda Meireles Gomes MOURA ${ }^{\mathrm{a}}$, Danielle BORDIN ${ }^{\mathrm{a}}$, Cristina Berger FADEL ${ }^{\mathrm{a}}$

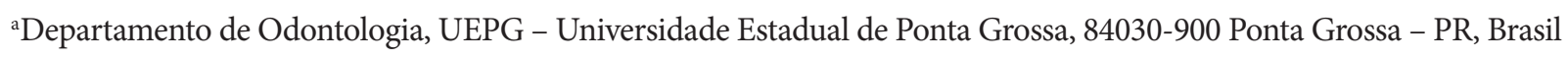

\begin{abstract}
Resumo
Objetivo: Compreender a significação do processo saúde-doença e do valor atribuído aos dentes, considerando o seu impacto estético e funcional na qualidade de vida de acadêmicos universitários. Metodologia: Desenvolveu-se um estudo transversal, quali-quantitativo, utilizando-se questionário semiestruturado e análise descritiva de dados. A amostra desta investigação constituiu-se de 70 acadêmicos formandos dos cursos de Odontologia e Engenharia Civil da Universidade Estadual de Ponta Grossa/PR. Resultado: Apontaram-se diferenças significantes entre os cursos para as variáveis: fatores que motivam a busca por um profissional da saúde; fatores relacionados ao próprio conceito de saúde; influência de um dente mal posicionado na qualidade de vida, e impacto frente à perda de um elemento dentário posterior. Conclusão: A formação acadêmica na área da saúde parece ter influência positiva sobre o entendimento dos determinantes do processo saúde-doença, os cuidados reservados à saúde e a valorização dental, com pouco alcance na abordagem conceitual de saúde.
\end{abstract}

Descritores: Processo saúde-doença; saúde bucal; formação de conceito; estudantes.

\begin{abstract}
Objective: To understand the significance of the health-disease process and the value assigned to the teeth considering its esthetic and functional impact on the life quality of the university academics. Metodology: It was developed a cross-sectional study, quali-quantitative, using semi-structured questionnaire and a data descriptive analysis. The sample consists on a 70 academic research graduates of courses in Dentistry and Civil Engineering, at the State University of Ponta Grossa - PR. Result: The significant differences between the courses for the following variables: factors that motivate the search for a health professional, factors related to the health concept, the influence of a tooth was misplaced in the life quality and the impact against the loss of a tooth later. Conclusion: The results show that the education in health seems to have a positive influence on the understanding the determinants of health-disease process, reserved for health care and dental recovery, with little range in the conceptual approach of health.
\end{abstract}

Descriptors: Health-disease process; oral health; concept formation; students.

\section{INTRODUÇÃO}

O homem busca significar e compreender as situações de seu cotidiano, para interpretar o mundo e nele se inserir, em seu processo único de vida. Em decorrência disso, dois elementos ganham importância singular: a saúde e a doença, especialmente por estabelecerem relações estreitas com a organização social e com as ações de busca e manutenção da saúde ${ }^{1}$.

Os estudos relacionados ao processo saúde-doença, de acordo com a época, assumem formas variadas de compreensão, viabilizando o surgimento de modelos explicativos que sublinham diferentes teses a esse respeito. O conhecimento sobre o processo saúde-doença está associado às concepções que explicam o mundo, os costumes, os valores e as crenças da sociedade em que é gerado, refletindo o pensamento dominante em dado momento histórico ${ }^{2}$. Entretanto, na trajetória evolutiva das concepções e da prática sobre a saúde e a doença, devem ser considerados alguns paradigmas que, começando com a visão mágico-religiosa, na Antiguidade, terminam na abordagem do modelo biomédico, ainda fortemente arraigado nos tempos de hoje, contrapondo-se com a atual e desejável multidimensionalidade da saúde ${ }^{3}$. Portanto, se a saúde e a doença são fenômenos com significados diferentes conforme a época e a cultura, evidencia-se a relevância de estudos que busquem a compreensão destas percepções junto a diferentes populações.

Ainda, cientes de que a imagem que o indivíduo faz de si - entendida como de caráter muito mais adotado do que construído - influencia a sua inserção e sua integração na sociedade, 
qualquer ruptura nos núcleos humanos pode provocar significantes implicações em seu cotidiano. Apesar de o espaço de construção estética do sujeito ser um processo subjetivo e mutável, observa-se claramente nos dias atuais uma maximização do fenômeno estético. Para Maffesoli (1996), a estética corporal é abordada enfatizando-se a questão da aparência, visualizada a partir de uma lógica grupal na qual se inserem diferentes grupos sociais. Desta forma, tal perspectiva, quando desdobrada ao âmbito da saúde bucal e de jovens institucionalizados, assume particular importância.

Frente ao exposto, os objetivos deste trabalho constituem-se na compreensão dos significados atribuídos à saúde e à doença, voltada aos acadêmicos universitários de formações distintas, e na significação do valor atribuído aos dentes, considerando-se o impacto da perda dentária em suas vidas.

\section{METODOLOGIA}

Desenvolveu-se um estudo transversal, de caráter exploratório, com a utilização conjunta de abordagem qualitativa e quantitativa, sendo o instrumento de coleta de informações empregado um questionário semiestruturado, adaptado de instrumento similar utilizado por Garbin et al. ${ }^{5}$ (2008) (Anexo).

A população objeto deste estudo foi composta pela totalidade de acadêmicos formandos dos cursos de graduação em Odontologia $(\mathrm{n}=52)$ e Engenharia Civil $(\mathrm{n}=31)$ da Universidade Estadual de Ponta Grossa/PR (ano base de formatura: 2011), constituindo-se, portanto, em uma amostra de conveniência.

O questionário foi submetido à pré-teste, por meio dos acadêmicos do ano anterior aos que seriam pesquisados. As questões buscaram investigar aspectos relacionados à visão acadêmica, no que se refere ao processo saúde-doença, ao valor por eles atribuído aos dentes e ao impacto causado em suas vidas frente a uma suposta perda dentária. Após esta etapa, considerada importante para a adequação do instrumento quanto ao texto, ao vocabulário utilizado e à sensibilidade das respostas, procedeu-se à aplicação do questionário. Em momento considerado oportuno aos acadêmicos investigados, de forma coletiva e em sala de aula, um único pesquisador, treinado para colher os dados e suprir supostas dúvidas, realizou a coleta de dados.

Para a apreciação dos dados relativos às questões fechadas, utilizou-se técnica de estatística descritiva e inferencial; para a análise de associação entre variáveis, foi utilizado o teste Qui-Quadrado ou o teste exato de Fisher, quando as condições para a utilização do teste Qui-Quadrado não foram verificadas. Os resultados foram considerados estatisticamente significantes para um valor de $\mathrm{p}<0,05$. Os dados foram digitados na planilha Excel (Microsoft Corp., Estados Unidos), e o programa utilizado para a obtenção dos cálculos estatísticos foi o Epi Info 3.5.1 (Centers for Disease Control and Prevention, Atlanta, Estados Unidos).

A questão norteadora "O que você entende por saúde?" foi tratada por meio de método qualitativo e suas respostas, agrupadas e pós-categorizadas de acordo com uma das técnicas da Análise de Conteúdo, a Análise Temática ${ }^{6}$. Nesta, busca-se o núcleo do sentido de uma comunicação e a presença de temas específicos que mostrem a relevância, os valores e os modelos inerentes ou escondidos no discurso.

Todos os participantes foram previamente informados sobre os propósitos da pesquisa e, quando em acordo, de livre e espontânea vontade, assinaram o Termo de Consentimento Livre e Esclarecido (TCLE).

O presente trabalho foi submetido e aprovado pela Comissão de Ética em Pesquisa da Universidade Estadual de Ponta Grossa/PR, registrado sob o parecer COEP n ${ }^{\circ} 65 / 11$.

\section{RESULTADO}

Por meio do processo de coleta de dados, obteve-se uma amostra de 70 acadêmicos formandos, sendo 43 pertencentes ao curso de Odontologia e 27, ao de Engenharia Civil. As perdas deram-se pela ausência do acadêmico no momento da aplicação do questionário ou por sua recusa em participar. Com relação à categorização por gênero, a maioria dos estudantes de Odontologia constituiu-se de mulheres $(74,4 \%)$ e, de Engenharia Civil, de homens (51,9\%), com uma faixa etária média de 22 anos para ambos os cursos.

A Tabela 1 apresenta as respostas fornecidas pelos alunos, quando questionados sobre os fatores que determinam a sua busca pelo auxílio de um profissional da saúde. Os resultados revelaram algumas diferenças significativas entre os cursos. Para a maioria dos acadêmicos de Odontologia (41,9\%), a procura por este profissional mostrou-se relacionada a uma consulta de

Tabela 1. Distribuição dos acadêmicos segundo os fatores que motivam a busca por um profissional da saúde. UEPG/PR, 2011

\begin{tabular}{|c|c|c|c|c|c|}
\hline & \multicolumn{4}{|c|}{ Acadêmicos formandos } & \multirow[b]{4}{*}{ p-valor } \\
\hline & \multirow{2}{*}{\multicolumn{2}{|c|}{$\begin{array}{c}\text { Odontologia } \\
(n=43)\end{array}$}} & \multirow{2}{*}{\multicolumn{2}{|c|}{$\begin{array}{c}\text { Engenharia civil } \\
\qquad(\mathbf{n}=27)\end{array}$}} & \\
\hline & & & & & \\
\hline & $\mathbf{N}$ & $\%$ & $\mathbf{N}$ & $\%$ & \\
\hline Esclarecimento de dúvidas & 4 & 9,3 & 1 & 3,7 & $0,376^{*}$ \\
\hline Consulta de rotina & 18 & 41,9 & 3 & 11,1 & $0,006^{* *}$ \\
\hline Dor ou desconforto leve, mesmo que não atrapalhem as atividades diárias & 11 & 25,6 & 6 & 22,2 & $0,749^{* *}$ \\
\hline Dor ou desconforto severo, que me impeçam de realizar as atividades diárias & 10 & 23,3 & 17 & 63,0 & $<0,001^{\star *}$ \\
\hline
\end{tabular}

*Teste exato de Fisher. ${ }^{\star *}$ Qui-Quadrado. 
rotina. Em contrapartida, grande parte dos alunos de Engenharia Civil (63\%) afirmou recorrer ao auxílio de um profissional da saúde somente frente à sensação de dor ou desconforto severo, capaz de impedir a realização de suas atividades diárias.

Outra demanda investigada foram os fatores relacionados com o seu próprio conceito de saúde (Tabela 2). Os formandos foram expostos a determinantes específicos, como 'hospital' e 'profissional da saúde', e também a variáveis amplas, relativas à determinação social do processo saúde-doença. A 'cultura', a 'moradia', a 'educação', o acesso ao 'profissional da saúde', à 'informação' e ao 'hospital', a 'renda' e o 'lazer' constituíram-se nas respostas acadêmicas mais díspares, com significância estatística entre os cursos.

Quando questionados sobre a influência de doenças bucais em sua saúde geral, todos os entrevistados, de ambos os cursos, afirmaram acreditar nesta interação.
A Tabela 3 apresenta as respostas fornecidas pelos alunos, considerando-se a influência de um dente mal posicionado na cavidade bucal sobre a sua qualidade de vida. Os dados obtidos revelaram um impacto maior entre os acadêmicos de Odontologia.

Outra investigação entre os formandos deu-se sobre a sua submissão a um suposto tratamento de clareamento dentário. A grande maioria dos entrevistados, de ambos os cursos, relataram que se submeteriam a este procedimento clínico, sendo o fator estético a justificativa mais apontada.

A Tabela 4 mostra a postura acadêmica frente à perda de um elemento dentário posterior. As respostas obtidas revelaram uma baixa tolerância ao dano da estrutura dentária, junto aos futuros cirurgiões-dentistas, visto que $83,7 \%$ submeter-se-iam imediatamente à colocação de uma prótese ou um implante dentário. Com relação à atitude dos futuros engenheiros, 51,9\% fariam esta escolha, sendo que $40,7 \%$ a cumpriria somente se,

Tabela 2. Distribuição dos acadêmicos segundo os fatores que se relacionam com o conceito de saúde. UEPG/PR, 2011

\begin{tabular}{|c|c|c|c|c|c|}
\hline & \multicolumn{4}{|c|}{ Acadêmicos formandos } & \multirow[b]{4}{*}{ p-valor } \\
\hline & \multirow{2}{*}{\multicolumn{2}{|c|}{$\begin{array}{c}\text { Odontologia } \\
(n=43)\end{array}$}} & \multirow{2}{*}{\multicolumn{2}{|c|}{$\begin{array}{c}\text { Engenharia civil } \\
(n=27)\end{array}$}} & \\
\hline & & & & & \\
\hline & $\mathbf{N}$ & $\%$ & $\mathbf{N}$ & $\%$ & \\
\hline Prática Esportiva & 40 & 93 & 23 & 85,2 & $0,253^{*}$ \\
\hline Cultura & 37 & 86 & 10 & 37 & $<0,001^{\star *}$ \\
\hline Moradia & 41 & 95,3 & 14 & 51,9 & $<0,001^{\star *}$ \\
\hline Educação & 41 & 95,3 & 13 & 48,1 & $<0,001^{\star *}$ \\
\hline Profissional da saúde & 41 & 95,3 & 21 & 77,8 & $0,033^{*}$ \\
\hline Informação & 39 & 90,7 & 16 & 59,3 & $0,002^{* *}$ \\
\hline Hospital & 36 & 83,7 & 17 & 63 & $0,049^{* *}$ \\
\hline Higiene Pessoal & 43 & 100 & 25 & 92,6 & $0,145^{\star}$ \\
\hline Saneamento básico & 43 & 100 & 26 & 96,3 & $0,386^{*}$ \\
\hline Alimentação & 43 & 100 & 25 & 92,6 & $0,145^{\star}$ \\
\hline Renda & 39 & 90,7 & 13 & 48,1 & $<0,001^{\star *}$ \\
\hline Lazer & 42 & 97,7 & 12 & 44,4 & $<0,001^{\star *}$ \\
\hline
\end{tabular}

${ }^{\star}$ Teste exato de Fisher. ${ }^{\star *}$ Qui-Quadrado.

Tabela 3. Distribuição dos acadêmicos segundo a influência de um dente mal posicionado em sua qualidade de vida. UEPG/PR, 2011

\begin{tabular}{|c|c|c|c|c|c|}
\hline & \multicolumn{4}{|c|}{ Acadêmicos formandos } & \multirow[b]{3}{*}{ p-valor } \\
\hline & \multicolumn{2}{|c|}{ Odontologia $(n=43)$} & \multicolumn{2}{|c|}{ Engenharia civil $(n=27)$} & \\
\hline & $\mathbf{N}$ & $\%$ & $\mathbf{N}$ & $\%$ & \\
\hline Não influenciaria, exceto se causasse dor ou desconforto & 6 & 14,0 & 6 & 22,2 & $0,282^{*}$ \\
\hline $\begin{array}{l}\text { Influenciaria pouco, uma vez que esse fato não iria interferir em } \\
\text { nenhum campo da minha vida }\end{array}$ & 9 & 20,9 & 12 & 44,4 & $0,037^{* *}$ \\
\hline $\begin{array}{l}\text { Influenciaria muito, pois me sentiria desconfortável e incomodado } \\
\text { com posicionamento dentário fora dos padrões considerados } \\
\text { atualmente perfeitos }\end{array}$ & 28 & 65,1 & 9 & 33,3 & $0,009^{* *}$ \\
\hline
\end{tabular}

\footnotetext{
*Teste exato de Fisher. ${ }^{* *}$ Qui-Quadrado.
} 
Tabela 4. Distribuição dos acadêmicos segundo o tratamento de escolha frente à perda de um elemento dentário posterior. UEPG/PR, 2011

\begin{tabular}{|c|c|c|c|c|c|}
\hline & \multicolumn{4}{|c|}{ Acadêmicos formandos } & \multirow[b]{3}{*}{ p-valor } \\
\hline & \multicolumn{2}{|c|}{ Odontologia $(n=43)$} & \multicolumn{2}{|c|}{ Engenharia Civil $(n=27)$} & \\
\hline & $\mathbf{N}$ & $\%$ & $\mathbf{N}$ & $\%$ & \\
\hline Nenhum, iria me adaptar facilmente à nova situação & 1 & 2,3 & 2 & 7,4 & $0,329^{*}$ \\
\hline $\begin{array}{l}\text { Me submeteria imediatamente à colocação de uma prótese/implante } \\
\text { dentário }\end{array}$ & 36 & 83,7 & 14 & 51,9 & $0,004^{* *}$ \\
\hline $\begin{array}{l}\text { Me submeteria à colocação de uma prótese/implante dentário, } \\
\text { caso, com o passar do tempo, sentisse dificuldade em me adaptar } \\
\text { à nova situação }\end{array}$ & 6 & 14 & 11 & 40,7 & $0,011^{\star *}$ \\
\hline
\end{tabular}

*Teste exato de Fisher. ${ }^{* *}$ Qui-Quadrado.

com o passar do tempo, sentisse dificuldade em adaptar-se à nova situação.

Entretanto, quando questionados sobre como a perda de um dente anterior, ocorrida de forma acidental ou indicada por um profissional, iria influenciar a sua vida, todos os entrevistados revelaram alta influência, uma vez que se sentiriam desconfortáveis e incomodados com um posicionamento dentário fora dos padrões considerados atualmente perfeitos.

Realizou-se ainda análise comparativa entre todas as variáveis expostas, por gênero, dentro de cada grupo, e esta característica mostrou-se significativa somente para a variável 'dor ou desconforto severo' $(\mathrm{p}=0,030)$, sendo o gênero masculino o maior responsável por esta implicação.

A exploração e a análise da questão aberta resultaram na categorização de três núcleos temáticos: (1) saúde como ausência de doença; (2) conceito normatizado de saúde; (3) visão ampliada de saúde, visando à reconstrução de significados que apresentem uma compreensão mais aprofundada da interpretação da realidade do grupo estudado. Os discursos mais representativos da realidade de cada grupo foram expostos, de acordo com as unidades temáticas.

O primeiro núcleo temático revelou o acadêmico que associa a sua saúde à completa ausência de doença, ou seja, quando não a relaciona com qualquer desequilíbrio evidente. Fizeram parte deste universo, 18,5\% dos acadêmicos de Engenharia Civil e 9,3\% de Odontologia.

"Pra mim saúde é a ausência completa de algum estado patológico." - Odontologia, 22 anos.

"Acho que saúde é ter disposição, não ter nenhuma doença, penso que é isso."- Engenharia Civil, 23 anos.

O segundo tema extraído relacionou-se ao conceito pré-estabelecido pela Organização Mundial de Saúde, o qual define saúde como o estado de completo bem-estar físico, mental e social, e não simplesmente a ausência de doença ou enfermidade. Dentre os graduandos que possuem esta visão, 33,3\% foram de Engenharia Civil e 72,1\% de Odontologia.

"Saúde é o bem estar físico, psíquico e emocional, não é somente a ausência de doença."- Odontologia, 21 anos.

"Bem estar físico, mental e social, tudo isso tem que estar bem junto para eu me sentir saudável."- Engenharia Civil, 23 anos.
O terceiro núcleo temático encontrado revelou uma visão ampliada e contemporânea de saúde, em que a terminologia 'qualidade de vida' foi amplamente citada; os entrevistados, ainda, relacionaram saúde a determinantes sociais amplos, como a educação, o saneamento básico, a cultura e o lazer, entre outros. Adequaram-se a esta temática 48,2\% dos futuros egressos de Engenharia Civil e 18,6\% de Odontologia.

"Bem-estar físico e mental. Conjunto de fatores. Assim como uma boa relação com a sociedade. Estar culturalmente e economicamente bem." - Odontologia, 23 anos.

"Saúde é tudo que nos traz boa qualidade de vida." - Engenharia Civil, 22 anos.

\section{DISCUSSÃO}

\section{Entendimento do Processo Saúde-doença}

A complexidade do cuidado em saúde é tema ainda pouco estudado no Brasil, apesar de sua relevância. O fenômeno do cuidado não é somente uma experiência subjetiva e material, na medida em que é também historicamente construído; assim, circunstâncias particulares, ideologias e relações de poder criam as condições sob as quais o cuidado pode ocorrer, as formas que assumirá e as consequências que terá sobre aqueles que o realizam e o recebem ${ }^{7}$.

Em um estudo qualitativo realizado com pós-graduandos em Enfermagem de uma universidade federal, com o objetivo de identificar o conceito de cuidado, os autores encontraram, dentre outras dimensões relacionadas, a sistematização do cuidado, relativa à prática do saber e do fazer técnico-científico ${ }^{8}$. Este resultado subsidia o exposto na Tabela 1 , visto que os estudantes de Odontologia pesquisados, supostamente munidos de saberes técnicos e científicos em saúde, mostraram-se mais suscetíveis à busca pelo cuidado, mesmo em situações que não demandassem impacto em suas atividades diárias. Entretanto, as respostas fornecidas pelos estudantes de Engenharia Civil endossam o cenário mundial, considerando-se que estudos epidemiológicos, nacionais e internacionais demonstram que a ocorrência de dor é a razão principal pela qual 75 a $80 \%$ das pessoas procuram os serviços de saúde . Vale lembrar que os indivíduos assumem 
posturas em saúde influenciadas pelo conceito de estética de determinada época, idade e tipo de cultura da comunidade na qual estão inseridos ${ }^{10}$.

Sabe-se que o modelo explicativo de interpretação do processo saúde-doença varia de acordo com as condições de existência e pela capacidade intelectiva do homem em cada momento histórico ${ }^{11}$. Neste estudo, a concepção de saúde apresentada pelos formandos perpassou por diversas significações.

Historicamente, as concepções ocidentais de saúde e doença foram fortemente influenciadas pelo paradigma biomédico, no qual o conceito de saúde era baseado unicamente na ausência de doença ${ }^{12}$. Vestígios desta concepção arcaica ainda se fazem presentes na nossa sociedade, como constatado no presente estudo, em que 18,5\% dos acadêmicos de Engenharia Civil e 9,3\% de Odontologia ainda apresentam esta visão. Outro estudo, desenvolvido com 204 acadêmicos universitários do Rio de Janeiro-RJ, também mostrou que a maioria dos entrevistados (43\%) ainda relaciona saúde com a ausência de doença ${ }^{13}$.

A industrialização trouxe consigo, além da modernização, o avanço tecnológico, a valorização da ciência em detrimento do homem e de seus valores, e os avanços na maneira de pensar do indivíduo. Certamente, estes fatos causariam também interferências em sua visão de saúde, o que efetivamente ocorreu em 1948, com a ampliação, pela Organização Mundial da Saúde, do conceito de saúde ${ }^{14}$. A partir de então, o enfoque iria além da centralização na doença e visava-se uma condição de perfeito bem-estar físico, mental e social. Embora esta definição tenha representado um avanço para a época, há tempos foi considerada irreal, ultrapassada e unilateral ${ }^{15}$, uma vez que trata o indivíduo de forma descontextualizada, desconsiderando a sua inserção socioeconômica-cultural. Apesar das críticas, este conceito ainda continua fortemente impregnado na representação de muitos indivíduos, normatizado socialmente, fato que pode ser evidenciado por meio do resultado desta pesquisa, na qual grande parte dos formandos de Odontologia (72,1\%) e de Engenharia Civil (33,3\%) expressaram seu entendimento de saúde sob este aspecto. Em estudo realizado com escolares do Ensino Fundamental do Estado de Santa Catarina, os aspectos relacionados ao senso comum também foram os que mais se associaram com o conceito de saúde ${ }^{16}$, evidenciando a propagação e a manutenção social desta categoria de pensamento.

Um conceito ainda mais ampliado de saúde vem sendo construído ao longo da história e caracteriza-se eminentemente pela determinação social da saúde e da doença. Neste, há a compreensão do referido binômio enquanto processo, resultado de um conjunto de fatores individuais e coletivos, sociais, econômicos, étnicos, religiosos, culturais, psicológicos, laborais, biológicos e ambientais, entre outros ${ }^{17}$.

Notou-se no presente estudo uma disparidade desta percepção entre os acadêmicos, uma vez que somente 18,6\% dos formandos em Odontologia avaliaram a saúde desta forma ampla, enquanto $48,2 \%$ dos de Engenharia Civil o fizeram. Em um estudo realizado com 948 universitários portugueses, dos quais $65,51 \%$ cursavam Enfermagem e 34,49\% eram provenientes de cursos não relacionados com a área da saúde, os autores não constataram diferença significativa entre as áreas de formação acadêmica e a percepção global de saúde ${ }^{18}$.

Frente a esta discrepância de resultado, pode-se notar, por meio das respostas, que muitos futuros engenheiros apresentavam conceitos pré-formados, identificados a partir da repetição, com algumas variantes, de frases, como "Saúde não é ausência de doença, é qualidade de vida”; nota-se que não há propriamente um aprofundamento de ideias em suas respostas. Característica semelhante foi apontada por outros autores, os quais julgam serem afirmações vazias de significado, revelando a dificuldade dos indivíduos de encontrarem algum sentido teórico e epistemológico para conceituar a saúde ${ }^{19}$. Neste sentido, as respostas dos futuros egressos de Odontologia, apesar do inesperado valor numérico $(18,6 \%)$, mostraram-se embasadas em argumentos teóricos, cientificamente fundamentados, fato que poderia sugerir certa influência de sua formação técnica.

Os resultados expressos na Tabela 2 reforçam esta afirmativa, uma vez que houve diferença significativa na identificação dos determinantes relacionados à saúde, entre ambos os cursos analisados. As diversas definições destes determinantes expressam, com maior ou menor nível de detalhe, o conceito atualmente bastante generalizado de que as condições de vida e trabalho dos indivíduos e de grupos da população estão relacionadas com sua situação de saúde ${ }^{14,17}$. Quando expostos a determinantes específicos, os formandos de Odontologia mostraram uma correlação mais expressiva dos fatores que se relacionam direta ou indiretamente à saúde - a exemplo de renda, lazer, hospital, cultura, moradia, educação, profissionais de saúde e informações - se comparados aos futuros engenheiros $(\mathrm{p}<0,005)$.

\section{Valorização Dental}

$\mathrm{Na}$ cultura moderna ocidental, a aparência é de suma importância e relaciona-se ao comportamento psicológico e social humano ${ }^{10}$. Sob esta perspectiva, a estética facial apresenta-se intimamente ligada à estética dental, a qual frequentemente se traduz por dentes claros, bem contornados e corretamente alinhados ${ }^{10,20}$, sendo o sorriso considerado um acessório fundamental do aspecto de cada indivíduo.

O conceito de beleza muda de tempos em tempos, porém o equilíbrio dos traços faciais é fator comum. Conforme a Tabela 3 , a preocupação por dentes bem alinhados na cavidade bucal é mais significante para os acadêmicos de Odontologia do que para os de Engenharia Civil, sendo que 65,1\% dos estudantes de Odontologia acreditam que se sentiriam desconfortáveis e incomodados com o posicionamento dentário fora dos padrões considerados atualmente perfeitos. Resultado este que corrobora com estudo semelhante ${ }^{5}$, no qual os autores justificam a alta influência de um dente desalinhando sobre a qualidade de vida de futuros cirurgiões-dentistas, muito provavelmente em virtude do valor agregado aos dentes e à estética dental durante o curso.

O posicionamento dentário também foi alvo de pesquisa realizada com 70 pacientes assistidos pela Universidade Metodista de São Paulo ${ }^{21}$, cujo maior interesse esteve relacionado com as mudanças no posicionamento dental, em especial dos dentes 
ântero-superiores, fato que confirmou a grande preocupação com a estética em detrimento da função mastigatória.

Esta intensa pressão social em torno do sorriso perfeito como padrão de beleza faz com que haja maior interesse no tratamento para clareamento dental ${ }^{20}$. Desta forma, as pessoas procuram dentes brancos, além do fator estético, também por razões sociais, profissionais e psicológicas ${ }^{10}$. Esta busca é observada por meio de várias pesquisas ${ }^{5}$, assim como pelos resultados do presente estudo, segundo os quais a grande maioria dos universitários de ambos os cursos revelou que se submeteria a um clareamento dentário, principalmente por finalidade estética. Indivíduos que relataram que não se submeteriam a este procedimento justificaram tal decisão principalmente pelo receio da sensibilidade dentária pós-tratamento e pela ausência de necessidade, dado semelhante ao de Garbin et al. ${ }^{5}$ (2008).

Por anos, a prática odontológica deu ênfase às extrações dentárias, entendida como caminho viável ao alívio das dores ${ }^{22}$. Entretanto, mais recentemente, com os avanços tecnológicos e científicos, vem sendo observada a preocupação com o impacto da perda dental na qualidade de vida das pessoas ${ }^{22}$. As consequências da perda dentária sobre as atividades diárias expõem-se de maneiras distintas entre a população, variando de irrelevantes para alguns ${ }^{23}$ a extremamente importantes para outros, podendo, inclusive, representar perda de oportunidades e gerar redução da autoestima ${ }^{24}$.

De acordo com a Tabela 4, a perda de um elemento dentário posterior mostrou-se intolerável para a maioria dos acadêmicos formandos de Odontologia, sendo que, nesta situação, $83,7 \%$ recorreriam à colocação de uma prótese ou um implante dentário de forma imediata. Dentre os formandos de Engenharia Civil, 51,9\% buscariam tratamento imediato, sendo que $40,7 \%$ postergariam a busca para o momento em que sentissem desconforto frente à nova situação. Nota-se preocupação explicitamente maior para os acadêmicos da área da saúde quanto à substituição por elementos artificiais a fim de superar limitações geradas pela ausência do dente natural em sua plena função. Novamente, o fato poderia estar ligado aos conhecimentos específicos adquiridos pelos estudantes de Odontologia, ao longo do curso de graduação, os quais lhes permitiriam atribuir ao órgão dentário o seu real valor, visto que têm profundo conhecimento de todas as suas funções ${ }^{25}$. No que se refere à ausência de um dente anterior, a repercussão negativa esteve relacionada à totalidade dos acadêmicos formandos de Odontologia e Engenharia Civil, o que corrobora com Garbin et al. ${ }^{5}$ (2008). Autores afirmam que a recuperação da função mastigatória do elemento dentário muitas vezes é colocada em segundo plano, por parte do paciente, principalmente quando há implicação conjunta de uma área estética ${ }^{21}$.

Ressalta-se que os resultados quantitativos encontrados neste trabalho devam ser vistos com cautela, frente ao pequeno tamanho da amostra e à diferença de composição de cada grupo, com um maior número de mulheres entre os formandos de Odontologia. Embora a análise de gênero realizada neste estudo não tenha obtido significância entre a grande maioria das variáveis pesquisadas, estudos que abordam questões relativas à temática 'gênero e saúde' identificam frequentemente mulheres como sendo mais estéticas e com uma percepção ampliada sobre a sua saúde, e homens, mais funcionais ${ }^{26,27}$. Toneli et al. ${ }^{28}$ (2010) encontraram, em seu estudo a respeito da percepção de usuários e profissionais da saúde sobre a saúde do homem, que as mulheres cuidam mais da saúde e o fazem preventivamente; de forma diversa, os homens não cuidam e o fazem curativamente, o que corrobora com o resultado deste estudo, no que se refere à variável gênero.

\section{CONCLUSÃO}

Apesar das limitações experimentadas por este estudo, impostas principalmente por sua amostra restrita, pôde-se verificar que:

- A formação acadêmica em Odontologia parece ter influência positiva sobre o entendimento de estudantes universitários no que se refere aos determinantes sociais do processo saúde-doença; entretanto, em sua abordagem conceitual, a aquisição de fundamentos científicos pareceu pouco influenciar na significação acadêmica;

- Quanto aos cuidados reservados à saúde, o desenvolvimento acadêmico na área específica sugere maior preocupação com a mesma, uma vez que 'consulta de rotina' foi o motivo mais apontado pelos estudantes de Odontologia e 'situação de dor ou desconforto severo', pelos acadêmicos de Engenharia Civil. Sugere-se que este resultado possa sofrer influência da variável gênero;

- Os futuros cirurgiões-dentistas atribuíram grande valor às dimensões de funcionalidade e estética do órgão dental, enquanto o comprometimento estético revelou-se a dimensão mais significante aos acadêmicos de Engenharia Civil.

\section{REFERÊNCIAS}

1. Vicini G. Abraço afetuoso em corpo sofrido: saúde integral para idosos. 3a ed. São Paulo: Editora SENAC; 2002.

2. Maranhão DG. O processo saúde-doença e os cuidados com a saúde na perspectiva dos educadores infantis. Cad Saúde Publica. 2000; 16: 143-8.

3. Carvalho RWF, Santos CNA, Oliveira CCC, Gonçalves SRJ, Novais SMA, Pereira MAS. Aspectos psicossociais dos adolescente de Aracaju (SE) relacionados à percepção de saúde bucal. Ciênc Saúde Coletiva. 2011; 16: 1621-8. http://dx.doi.org/10.1590/S141381232011000700098

4. Maffesoli M. No fundo das aparências. Petrópolis: Editora Vozes; 1996.

5. Garbin CAS, Fadel CB, Garbin AJI, Saliba NA. O valor atribuído aos dentes: um estudo com acadêmicos de Odontologia e Medicina Veterinária. Rev Odontol UNESP. 2008; 37: 47-52.

6. Minayo MCS. O desafio do conhecimento: pesquisa qualitativa em saúde. 11ª ed. São Paulo: Hucitec; 2008. 
7. Reverby S. A caring dilemma: womanhood and nursing in a historical perspective. Nurs Res. 1987; 36: 5-11. PMid:3543850.

8. Erdmann AL, Nascimento KC, Marcelino G, Ribeiro AJ. As interfaces do cuidado pelo olhar da complexidade: um estudo com um grupo de pós-graduandos de Enfermagem. Esc Anna Nery R Enferm. 2005; 9: 411-20. http://dx.doi.org/10.1590/S1414-81452005000300009

9. Brasil. Ministério da saúde. Portaria n. ${ }^{\circ}$ 19/GM de 03 de janeiro de 2002. Brasilia, DF; 2002.

10. Mandarino F. Clareamento dental. 2003 [citado em 2011 Dez 10]. Disponível em: http://www.forp.usp.br/restauradora/dentistica/temas/ clar_dent/clardent.pdf

11. Barata RCB. A historicidade do conceito da causa. In: Carvalheiro JR, organizador. Textos de apoio: epidemiologia 1. $2^{\mathrm{a}}$ ed. Rio de Janeiro: SDE-ENSO/ABRASCO; 1990. p.13-25.

12. Kluthcovsky ACGC, Takayanagui AMM. Community Health Agent: a literature review. Rev Latino-Am Enfermagem. 2006; 14: 957-63. PMid:17294032. http://dx.doi.org/10.1590/S0104-11692006000600019

13. Andrade Junior H, Souza MA, Brochier JI. Representação social da educação ambiental e da educação em saúde em universitários. Psicologia: Reflexão e Crítica. 2004; 17: 43-5.

14. Buss PM, Pellegrine Filho A. A Saúde e seus determinantes sociais. PHYSIS: Rev Saúde Coletiva. 2007; 17: 77-93.

15. Segre M, Ferraz FC. O conceito de saúde. Rev Saúde Pública. 1997; 31: 538-42. http://dx.doi.org/10.1590/S0034-89101997000600016

16. Bottan ER, Campos L, Verwiebe APS. Significado do conceito de saúde na perspectiva de escolares do ensino fundamental. RBPS. 2008; 21: 240-5. http://dx.doi.org/10.5020/18061230.2008.p240

17. Reis AM, Soares CB, Campos CMS. Processo saúde-doença:concepções do movimento estudantil da área da saúde. Saúde Soc. 2010; 9: 347-57.

18. Matos APS, Sousa-Albuquerque CM. Estilo de vida, percepção de saúde e estado de saúde em estudantes universitários portugueses: influência da área de formação. International Journal of Clinical and Health Psychology. 2006; 6: 647-63.

19. Minayo MCS, Hartz ZMA, Buss PM. Qualidade de vida e saúde: um debate necessário. Ciênc Saúde Coletiva. 2000; 5: 7-18. http://dx.doi. org/10.1590/S1413-81232000000100002

20. Portolani Junior MV, Candido MSM. Efeito dos agentes clareadores sobre as estruturas dentais. Rev Odontol UNESP, 2005 ; $34: 91-4$.

21. Maltagliati LA, Montes LAP. Análise dos fatores que motivam os pacientes adultos a buscarem o tratamento ortodôntico. Rev Dental Press Ortodon Ortop Facial. 2007; 12: 54-60.

22. Lacerda JT, Simionato EM, Peres KG, Peres MA, Traebert J, Marcenes W. Dental pain as the reason for visiting a dentist in a Brazilian adult population. Rev Saúde Pública. 2004; 38: 453-8. http://dx.doi.org/10.1590/S0034-89102004000300017

23. Mesquita FAB, Vieira S. Impacto da condição autoavaliada de saúde bucal na qualidade de vida. RGO. 2009; 57: 401-6.

24. Davoglio RS, Aerts DRGC, Abegg C, Freddo SL, Monteiro L. Fatores associados a hábitos de saúde bucal e utilização de serviços odontológicos entre adolescentes. Cad Saúde Pública. 2009; 25: 655-67. http://dx.doi.org/10.1590/S0102-311X2009000300020

25. Lima DC, Saliba NA, Garbin AJI, Fernandes LA, Garbin CAS. A importância da saúde bucal na ótica de pacientes hospitalizados. Ciênc Saúde Coletiva. 2011; 16: 1173-80. http://dx.doi.org/10.1590/S1413-81232011000700049

26. Biber SH. Am I thin enough yet?: the cult of thinness and the commercialization of beauty. Oxford: Oxford University; 1989.

27. Kiefer I, Leitner B, Bauer R, Rieder A. Body weight: the male and female perception. In: Sozial Präventivmed. Basel: Birkhäuser, 2000.

28. Toneli MJF, De Souza, MGC, Muller RCF. Masculinidades e práticas de saúde: retratos da experiência de pesquisa em Florianópolis/SC. Physis [periódico na Internet]. 2010 [citado em 2012 Jan 15]; 20(3):973-994. Disponível em: http://www.scielo.br/scielo.php?script=sci_ arttext\&pid=S0103-73312010000300015

\section{CONFLITOS DE INTERESSE}

Os autores declaram não haver conflitos de interesse.

\section{AUTOR PARA CORRESPONDÊNCIA}

Danielle Bordin

Rua Dr. Francisco Beltrão, 310, 85550-000 Coronel Vivida - PR, Brasil

e-mail: daniellebordin@hotmail.com

Recebido: 13/07/2012

Aprovado: 13/09/2012 


\section{ANEXO. QUESTIONÁRIO}

Idade: Sexo: ( ) Masc. ( ) Fem.

Acadêmico formando: ( ) Odontologia ( ) Engenharia Civil

1. O que você entende por saúde?

2. O que motiva você a buscar o auxílio de um profissional da saúde?

( ) Esclarecimento de dúvidas.

( ) Consulta de rotina.

( ) Quando estou com dor e/ou desconforto leve, mesmo que não atrapalhem as minhas atividades diárias.

( ) Quando estou com dor e/ou desconforto severo, que me impeçam de realizar as minhas atividades diárias.

( ) Outro. Qual?

3. Dentre as alternativas abaixo, assinale os itens que se relacionam com a sua saúde.
( ) Pratica esportiva
( ) Cultura
( ) Moradia
( ) Médico/ dentista/psicólogo
( ) Informação
( ) Hospital
( ) Higiene pessoal
( ) Saneamento básico
( ) Alimentação
( ) Renda
( ) Lazer
( ) Educação

4. Você acredita que doenças da boca, como cárie, gengivite e ausência de dentes afetam a sua saúde geral?

( ) Sim ( ) Não

5. De que forma um dente mal posicionado em sua boca (levemente desalinhado) iria influenciar sua qualidade de vida?

( ) Não influenciaria, exceto se causasse dor ou desconforto.

( ) Influenciaria pouco, uma vez que esse fato não iria interferir em nenhum campo da minha vida (estudo, trabalho, relacionamentos afetivos, autoestima).

( ) Influenciaria muito, pois me sentiria desconfortável e incomodado com posicionamento dentário fora dos padrões considerados atualmente perfeitos.

6. Você se submeteria a um tratamento de clareamento dentário?

( ) SIM. Por quê?

( ) NÃO. Por quê?

7. Caso você tenha que se submeter a uma extração dentária posterior - "dente do fundo da boca" (exceto dente do siso), sem envolvimento estético aparente, qual o tratamento de sua escolha?

( ) Nenhum, iria me adaptar facilmente à nova situação.

( ) Me submeteria imediatamente à colocação de uma prótese / um implante dentário.

( ) Me submeteria à colocação de uma prótese / um implante dentário, caso, com o passar do tempo, sentisse dificuldade em me adaptar à nova situação.

8. Como a perda de um dente anterior - "dente da frente da boca" - ocorrida de forma acidental ou indicada por um dentista, iria influenciar a sua vida?

( ) Não influenciaria.

( ) Influenciaria pouco, uma vez que esse fato não iria interferir em nenhum campo da minha vida (estudo, trabalho, relacionamentos afetivos, autoestima).

( ) Influenciaria muito, pois me sentiria desconfortável e incomodado com a ausência dos dentes, fora dos padrões considerados atualmente perfeitos. 